\title{
O teatro coreano contemporâneo Duas abordagens à história
} Yun-Cheol Kim



Um estilo de morte, enc. Yun-Taek Lee.

é editor de uma revista de teatro coreana

Professor na Escola Nacional de Teatro da Coreia do Sul. É ainda membro do seu Comité

Executivo e Vice-

Presidente da

Associação

Internacional de

Críticos de Teatro.
I. A Coreia é um pequeno país com uma longa história. A realidade e o mito ajudaram ambos a alongar a extensão dessa história até aos 5.000 anos, mas a história registada da Coreia começa, de facto, a surgir por volta do século IV a.C. À medida que se avança da pré-história para a história registada, e da mais remota para a mais recente, essa longa história foi sendo crescentemente ameaçada tanto por inúmeras invasões estrangeiras - mais de quinhentas, ao que consta -, sobretudo por parte da China e do Japão, como, a nível interno, por várias decisões políticas equivocadas, tomadas por governantes ora incompetentes, ora totalitários.

A Coreia vê-se a si própria como racialmente homogénea, embora se encontre, de qualquer forma, dividida entre os governantes e os governados, entre a esquerda e a direita, entre o ter e o não ter. 0 grande sofrimento do povo é a consequência visível de uma política medíocre. Até recentemente, esta dor tem sido tão aguda que os intelectuais coreanos tenderam a cultivar, em geral, uma atitude cínica e crítica em relação à sua própria história. Os dramaturgos não são excepção. E são-no ainda menos, particularmente no que respeita a sua história recente. A história tornou-se um trauma nacional e apresenta-se agora como o tema mais frequente em todos os tipos de formas dramáticas: teatral, musical, televisiva

Entre os dramaturgos desta vaga, concentrarei a minha atenção em dois deles, Tae-Suk Oh (1940-) e Yun-Taek Lee (1952-), que partilham inúmeras semelhanças aparentes. Em primeiro lugar, encenam habitualmente as suas próprias peças. A sua criação de imagens cénicas coaduna-se, portanto, com os textos. Em segundo lugar, ambos são extremamente conscientes - ou obcecados, se se preferir -, em termos históricos. Aqui terminam, porém, as suas semelhanças. As suas abordagens e atitudes em relação à história divergem nítida e consistentemente. A diferença e cinematográfica.



na sua dramaturgia manifesta-se, para além disso, na invenção e na produção das imagens cénicas de cada um.

II. Tae-Suk Oh, mentor do segundo dramaturgo de que me ocuparei, vem escrevendo peças há mais de 45 anos e, desde o início da década de 1980, que se tem debruçado sobre traumas históricos. Nos anos oitenta, concentrou-se na dramatização da culpa colectiva daqueles civis que sobreviveram à Guerra da Coreia, por colaborarem no assassinato dos seus parentes e vizinhos sob coacção armada, forçados, alternadamente, pelos soldados do Norte e pelos soldados do Sul. Oh viveu a guerra enquanto jovem e testemunhou a morte do seu tio, esfaqueado pela população da sua própria vila. Bicicleta (1983) é, de longe, entre as peças de guerra, o seu melhor trabalho, e lida com a sua memória daquele terrivel incidente. Bang-Ock Kim já chamou a atenção para o modo singular como o dramaturgo sul-coreano aborda a estrutura e a construção de imagens: "Acontecimentos e memórias misturados reúnem-se no inconsciente do funcionário público de uma vila, que caminha numa viela escura a meio da noite, criando uma rede labirintica, que representa a mente prototípica das gentes rurais da Coreia". Basicamente, a peça recria o passado e relaciona-o com o presente. Tratase de uma peça-dentro-da-peça e de uma viagem ao inconsciente. Uma vez alcançado, o inconsciente reconciliase com o consciente. Esta reconciliação dramatúrgica do passado com o presente, das vitimas com os algozes, sob a forma de metateatro, vem sendo desde então a abordagem consistente de Oh em relação à história.

A reconciliação ocorre de maneira mais dramática embora de modo similar, em Um prisioneiro de mil anos (1998). A peça justapõe os assassinatos históricos de dois presidentes, logo após a libertação da Coreia do domínio japonês, em 1945, e um holocausto coreano: o massacre dos libertadores da cidade de Kwangju pelo ditador militar, 

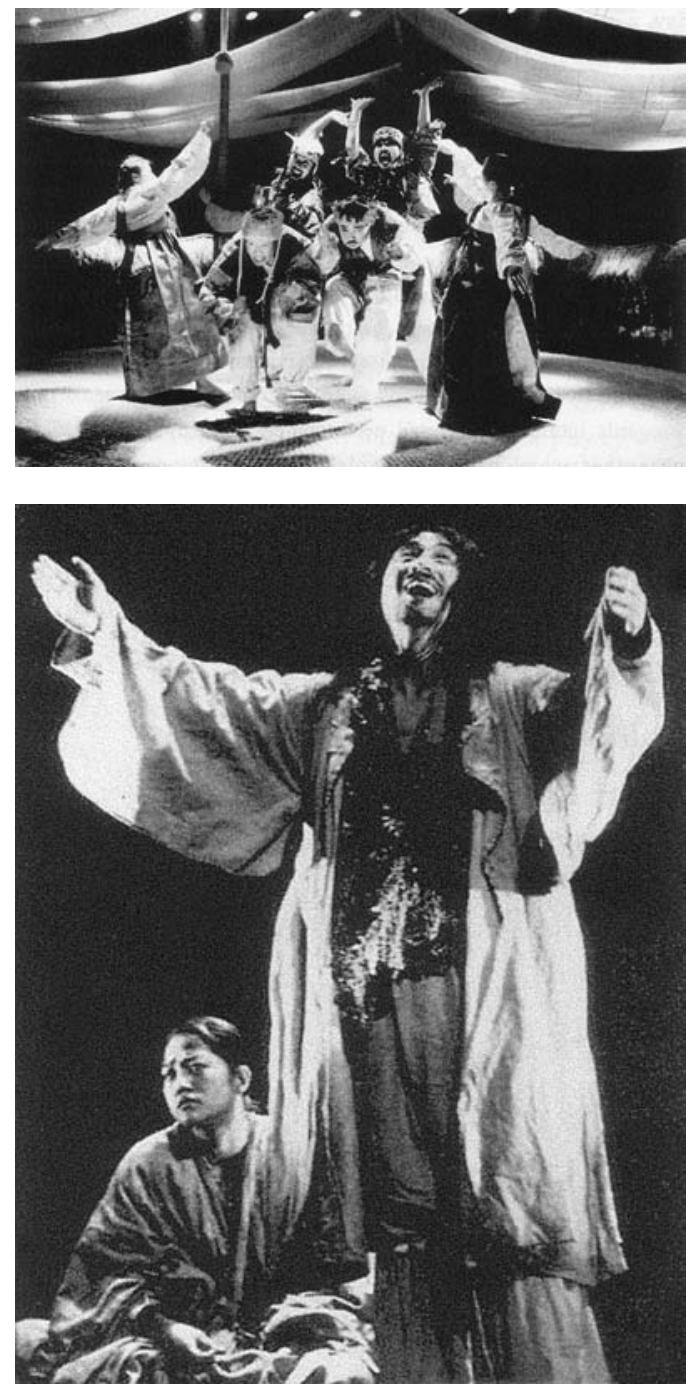

no ano relativamente recente de 1980. Mais uma vez, tratase de metateatro, o qual tem início num sonho que torna possível o encontro dos assassinos de diferentes períodos históricos. Cada um desses assassinatos corresponde a um facto histórico. A justaposição que Oh efectua, para além de os situar num asilo contemporâneo, revela-se contudo como uma criação ou contextualização da história do ponto de vista do presente. Ele trata a história como ficção; não tenta ser fiel aos factos históricos. Isto é, ele lê a história como ela deveria ter sido. Através desta modificação, Oh lança um olhar compadecido sobre os agressores, que ele acredita serem vítimas daqueles tempos de turbulência

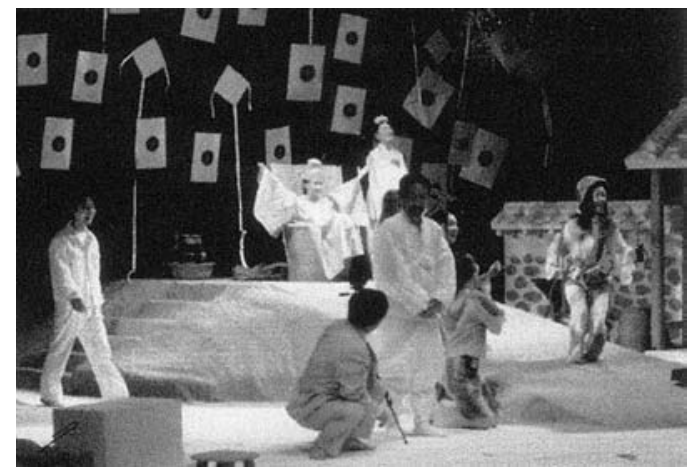

A mulher de Choonpung enc. Tae-Suk Oh.

Pavilhão no céu, enc. Tae-Suk Oh.

política. A reconciliação entre vitimas e agressores é encenada na conclusão da peça através do ritual xamanístico para apaziguar os mortos. Oh acredita sinceramente que a reconciliação é possível, mas apenas quando as vítimas perdoam aos agressores.

Quando dirige as suas próprias peças, Oh prefere um espaço quase vazio, de modo a poder facilmente alternar dimensões temporais (o passado e o presente) e espaciais (vida e morte) ou a fazê-las interagir num nivel de simultaneidade. Para Oh, a eficiência funcional é muito mais importante do que a beleza estética. É sempre ele próprio a projectar os seus cenários e adereços, os quais se apresentam simultaneamente como toscos e lúdicos. A sua eficiência funcional mostra-se, todavia, perfeita para apoiar as suas abordagens dramatúrgicas - e estas são baseadas nos princípios das artes performativas coreanas tradicionais, nas quais o tempo e o espaço são determinados mais pela necessidade dramática do que pela lógica situacional.

III. Ao contrário de Oh, o seu protegido e arqui-rival, Yun-Taek Lee utiliza cenários completos, desenhados de forma bastante peculiar, como ambientes para as suas ficções dramáticas. Ele convida, habitualmente, cenógrafos de renome para criar espectáculos realistas - não de um realismo fotográfico, mas antes atmosférico. Os figurinos e os adereços são frequentemente exagerados para efeitos de caricatura. Em termos gerais, os seus elementos visuais combinam realismo e expressionismo.

As imagens cénicas reflectem uma dramaturgia que se apresenta, por um lado, como convencional, no que respeita a sua estrutura dialéctica, e, por outro, como pósmoderna, na medida em que normalmente emprega, na encenação da história passada, signos contemporâneos tomados de empréstimo a outros meios expressivos. Enquanto Tae-Suk Oh tenta reconciliar o presente doloroso

\section{O sentimento,} divinamente, enc. Yun-Taek Lee. 
e o passado imperdoável, Lee serve-se de matéria-prima histórica para sublinhar o papel dos intelectuais na luta contra a corrupção política. Lee procura descobrir individuos problemáticos que há muito foram sepultados em factos históricos e ideias fixas, intelectuais que possam servir de modelo neste nosso tempo de turbulência política e crise humanitária.

Duas peças em particular são bons exemplos da sua dramaturgia: Rei Yon-San: Homem problemático (1995) e Nam-Myung Jo: Um homem com experiência (2002). Ambas se ocupam da história coreana de há 500 anos atrás, quando a dinastia Yi era governada pelo nosso monarca mais sangrento, Yon-San, e era extrema a rivalidade entre os membros da família real. Em Yon-San, Lee retrata um rei ditador que violentamente extirpou a corrupção da ordem social, mas que falhou ao não conseguir ultrapassar a sua vingança pessoal pela morte injusta da mãe. Numa das cenas iniciais, no decurso de um ritual invocativo, o rei mata a avó, que havia planeado o castigo capital da sua mãe, atingindo a cabeça dela com a sua própria cabeça, como o faria um qualquer famoso lutador coreano profissional de luta livre da actualidade. Esta caricatura farsesca do matricídio é um inteligente artifício pósmoderno deste dramaturgo-encenador, por meio do qua ele consegue escapar à dura crítica moral do público, que jamais desculparia o assassinato de uma avó, sejam quais forem as circunstâncias. Empregando um significante tirado de empréstimo de um desporto moderno, Lee acrescenta um novo sentido ao matricídio histórico.

À medida que o reinado de Yon-San se torna progressivamente sangrento, Lee muda o foco dramático do rei Yon-San para o seu leal confidente, Cho-Sun Kim, que se mantém contra o seu governo cruel. 0 rei procura silenciá-lo pela tortura, decepando as suas mãos e arrancando a sua língua. Ainda assim, Kim recusa-se a ceder acabando por ser finalmente decapitado pelo seu senhor. A imagem cénica torna-se bastante artaudiana. 0 confidente-tornado-principal-líder-da-oposição chega inclusivamente a surgir num sonho do rei, criticando as suas más acções, tal como acontece com Banquo em Macbeth. Esta caracterização é, em grande parte, uma criação de Lee, à margem da verdade histórica, colocada no contexto contemporâneo da liberdade de expressão sob um regime totalitário. Lee descobre um novo homem problemático na figura do rei Yon-San: por um lado, demonstra a sua compaixão para com ele, e por outro, cria um novo intelectual com a coragem heróica de, sob risco da sua própria morte, se manifestar contra a corrupção política e defender a justiça social.
Cerca de cinquenta anos após a existência do rei YonSan, Lee descobriu uma outra figura histórica, capaz de servir como modelo aos intelectuais contemporâneos. Lee concentra-se no auto-exílio de Jo numa zona rural, uma figura que se recusa a prestar serviço como simples oficial na capital. 0 reino encontra-se mergulhado numa disputa pelo poder entre os membros da família real, liderada pela mãe do rei. Apesar do caos político e do enorme sofrimento do povo, os intelectuais não se mostram nem oportunistas nem silenciosos. É Jo, no momento derradeiro da peça, quem arrisca a sua vida e escreve uma petição ao rei, exigindo que ele purgue a corte livrando-se tanto da sua mãe como dos seus apoiantes. Nam-Myung Jo funciona como outra chamada de atenção para que os intelectuais de hoje participem nos movimentos políticos e sociais, a bem da democracia, sobretudo quando a maioria se torna oportunistamente silenciosa sob um governo particularmente beligerante. Mais uma vez, Lee faz uso de muito humor negro e grotesco, bem como de significantes contemporâneos associados a imagens artaudianas.

IV. Nem Oh nem Lee estão interessados na história tal como ela é. Eles não se importam de criar a história para a tornar contemporânea. Ambos compõem cenas dramáticas e constroem imagens cénicas tendo como base a necessidade dramática, em detrimento da lógica situacional. Todavia, a clara diferença que os distingue reside no facto de o universo dramático de Oh, embora sempre clamando pela reconciliação de dois partidos incompatíveis, se mostrar muito mais negro, com a sua comunhão expressionista e imaginativa entre o presente que vive e o passado que morreu. Oh recria a história para a apresentar como ela deveria ter sido. Porque sabemos que, na realidade, as coisas não se passaram assim, a sua abordagem acaba, de alguma forma, por limitar a sua força persuasiva. Por seu turno, Lee redescobre a história e faz-nos lê-la numa perspectiva diferente. A sua recriação da história mantém a dimensão factual - isto é, dentro da dimensão do realismo físico - e é, deste modo, muito concreta. Através desta apresentação de modelos históricos para os intelectuais contemporâneos, reafirma-se a possibilidade de aperfeiçoamento humano - o qual tem sido, desde há muito, procurado nos heróis trágicos da tradição dramática ocidental. Seria lamentável se uma tradição de semelhante profundidade fosse esquecida no Oriente!

Tradução de Marta Costa Dias 